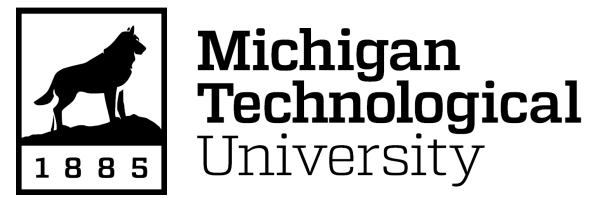

Michigan Technological University Digital Commons @ Michigan Tech

Dissertations, Master's Theses and Master's Reports

2020

\title{
BUCKLING LOAD STUDY ON POP NUT (RIVET) USING FINITE ELEMENT ANALYSIS
}

Saurabh Shankar Shegokar

Michigan Technological University, ssshegok@mtu.edu

Copyright 2020 Saurabh Shankar Shegokar

\section{Recommended Citation}

Shegokar, Saurabh Shankar, "BUCKLING LOAD STUDY ON POP NUT (RIVET) USING FINITE ELEMENT ANALYSIS", Open Access Master's Report, Michigan Technological University, 2020.

https://doi.org/10.37099/mtu.dc.etdr/1080

Follow this and additional works at: https://digitalcommons.mtu.edu/etdr

Part of the Computer-Aided Engineering and Design Commons, Mechanics of Materials Commons, Other Mechanical Engineering Commons, and the Structural Materials Commons 
BUCKLING LOAD STUDY ON POP NUT (RIVET) USING FINITE ELEMENT ANALYSIS

By

Saurabh Shankar Shegokar

\begin{abstract}
A REPORT
Submitted in partial fulfillment of the requirements for the degree of MASTER OF SCIENCE

In Mechanical Engineering
\end{abstract}

MICHIGAN TECHNOLOGICAL UNIVERSITY

2020

(C) 2020 Saurabh Shankar Shegokar 
This report has been approved in partial fulfillment of the requirements for the Degree of MASTER OF SCIENCE in Mechanical Engineering.

Department of Mechanical Engineering - Engineering Mechanics

\author{
Report Advisor: $\quad$ Dr. Gregory Odegard \\ Committee Member: Dr. Susanta Ghosh \\ Committee Member: Dr. Paul Van Susante \\ Department Chair: $\quad$ Dr. William W. Predebon
}




\section{Table of Contents}

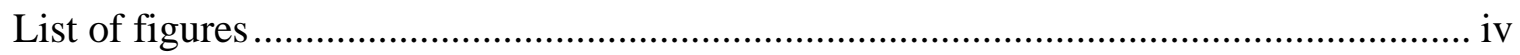

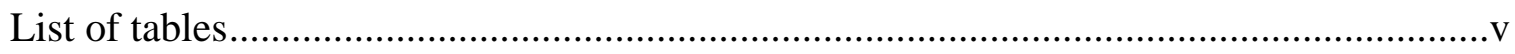

Acknowledgements............................................................................................... vi

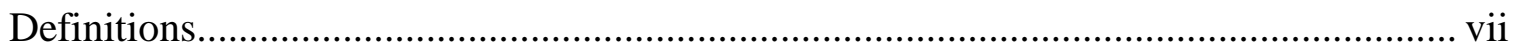

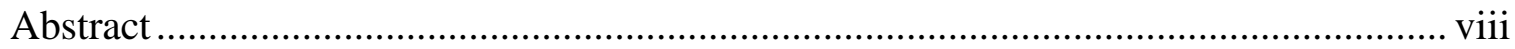

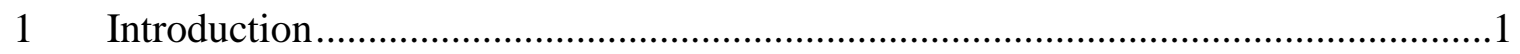

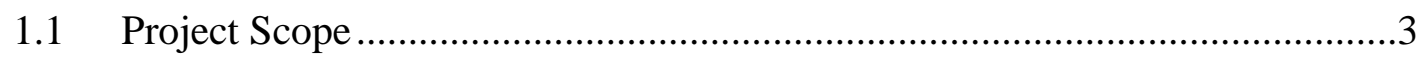

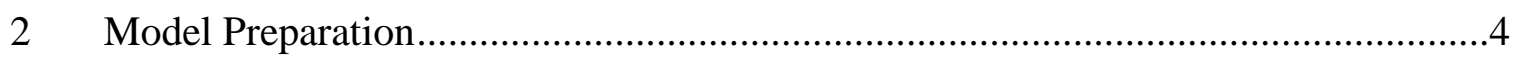

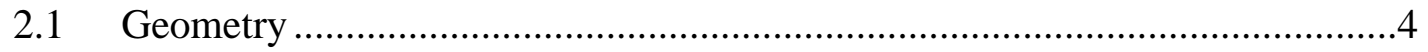

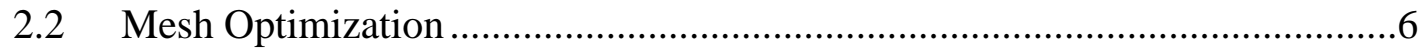

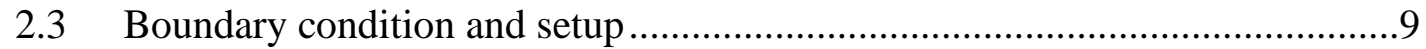

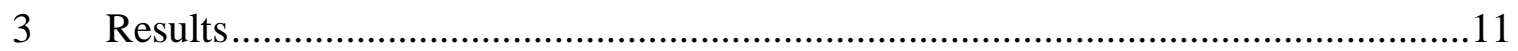

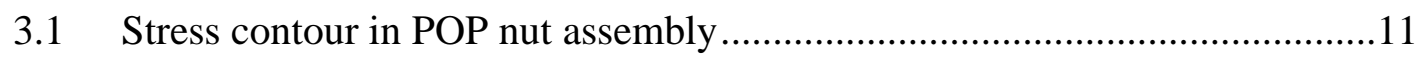

3.2 Testing results and Finite Element Analysis results ........................................14

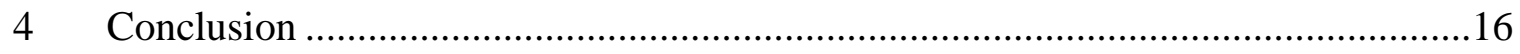

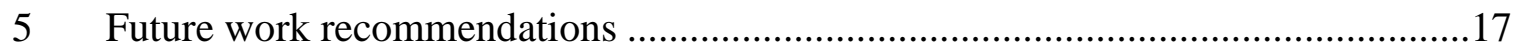

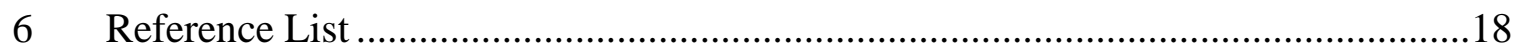




\section{List of figures}

Figure 1-1 POP Nut drawing with dimensions and tolerances provided by Stanley Black

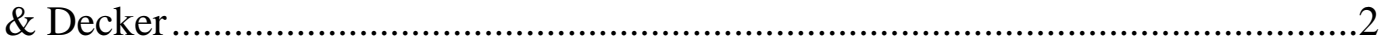

Figure 2-1 POP Nut section with sheet metal..............................................................

Figure 2-2 CAD model of POP nut modeled in Nx.......................................................

Figure 2-3 POP Nut mesh optimization study with global mesh seeding. .........................6

Figure 2-4 CAX4R axisymmetric element suitable to analyze structure with

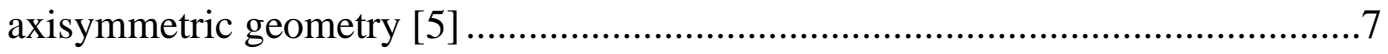

Figure 2-5 Meshed POP Nut section assembly with global mesh seeding of $0.05 \mathrm{~mm}$......7

Figure 2-6 Boundary conditions and reference points in model setup ...............................9

Figure 2-7 Contact surfaces in POP nut assembly. On left surface-to-surface contact and

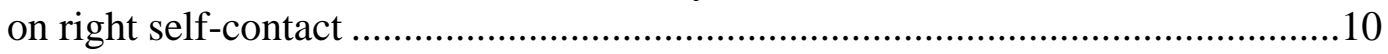

Figure 2-8 Tie constraints in POP nut assembly. From left between the top surface of rivet and reference point on upper rigid elements, between reference point on lower rigid elements and POP nut collar, and between Sheetmetal and POP nut collar, and between the collar of a rivet

Figure 3-1 Stress distribution in POP nut assembly after $6 \mathrm{~mm}$ displacement.................11

Figure 3-2 Stress singularity observed in the Sheetmetal part..........................................12

Figure 3-3 Displacement contour for POP nut assembly................................................12

Figure 3-4 POP nut assembly stress contour at every 25 timesteps. ...............................13

Figure 3-5 Buckling load vs displacement curve from physical testing ...........................14

Figure 3-6 Buckling load vs Displacement curve comparison ..........................................14

Figure 3-7 $180^{\circ}$ and $360^{\circ}$ sweep of POP nut assembly at the final timestep...................15 


\section{List of tables}

Table 1-1. The material composition used in physical testing ...........................................3

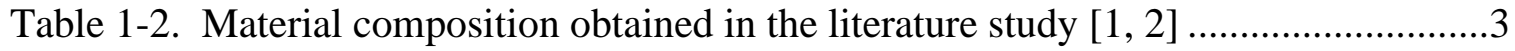

Table 2-1. POP Nut dimensions are taken from drawing provided by Stanley Black \&

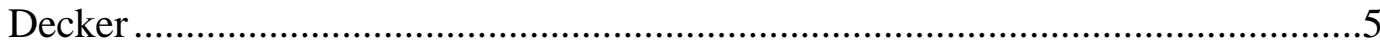

Table 2-2 Material properties used to define POP nut in analysis...................................5

Table 2-3 Mesh size with stress values from the mesh sensitivity study.........................6 


\section{Acknowledgements}

I would like to thank my advisor, Dr. Gregory Odegard for giving me this opportunity to work on this project. I am grateful for his constant support and guidance throughout my master's degree. Working under his guidance was a wonderful learning opportunity for me. I learned a lot from him, His feedback helped me succeed in this project as well as in academics. His guidance helped me become a better learner and a good engineer.

I would like to thank Thomas Wood for introducing me to this project. His findings and support helped me define my project objective and goal. I am thankful for his guidance in helping me understand the background of this project. His timely feedback was helpful throughout the project.

I would like to thank my committee members Dr. Susanta Ghosh and Dr. Paul Van Susante for their feedback and invaluable time. Dr. Susanta Ghosh helped me in understanding the Finite Element Methods. His guidance on Finite Element Methods helped me in clearing many doubts.

I would like to thank my research group for their continuous feedback and motivation.

Lastly, I would like to thank my family for their constant encouragement and support throughout my journey. 


\section{Definitions}

$\mathrm{H}$-refinement or H-convergence is the process of decreasing the size of the elements to improve the approximation over geometry.

Hourglass control is a method to suppresses the distortion in an element while used in reduced integration without causing any strain.

Stress Singularity is a place or point in the finite element analysis where theoretically the stresses are infinite. 


\section{Abstract}

This study highlights the material behavior in riveting operation that includes buckling load analysis using ABAQUS. Finite Element Analysis is used to find the buckling load vs. Displacement results and validated with the results obtained in physical testing of rivet (POP Nut). A mesh sensitivity study is performed using ABAQUS to understand the optimum mesh size for this analysis. An axisymmetric model with contact properties is created and simulated to reduce the simulation time using ABAQUS. The results obtained through Finite Element Analysis show a good resemblance with the testing results. Design changes were suggested to achieve better results that will reduce minute deviations present in the current simulation study. This study provides necessary details to continue FEA analysis on similar geometry with added complexities and different materials. 


\section{Introduction}

Rivets have been an essential use in many industrial applications. From household products to the big enclosures. They have played an important role in the automotive industry and the locomotive industry. The function of a rivet is to join two parts and provide sufficient stiffens to the system. Over a period, many joining processes proved to be more efficient than riveting operation but, simplicity of operation and cost has been a prime advantage for rivets over other joining processes. Although riveting cannot offer a smooth A-surface to the system it is used on a large scale for joining operations. Rivets come in different forms and nowadays based on application rivets are being modified. Basic types of rivets are solid, blind, split, and tubular. There are several sub-groups present in each type of rivet. Rivet has two important fundamentals which are shape and material. The shape of rivet provides the essential operational ease and material gives the strength.

A schematic showing riveting operation can be summarized as follows

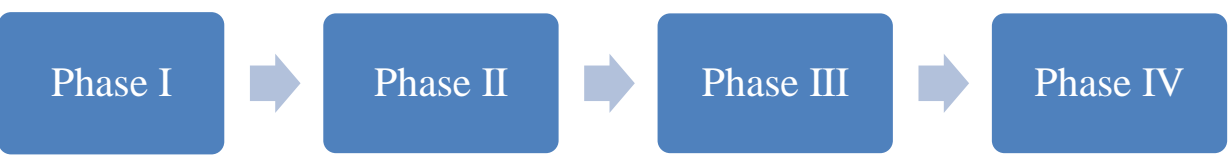

In Phase-I Thread aligning of a blind rivet is performed while in Phase-II blind rivet nut is fed into the workpiece. Phase-III is the part where threaded mandrel is retracted, and blind rivet nut is pulled at the top collar. Finally, in Phase-IV the mandrel is unthreaded, and the riveting process is completed.

Why Finite Element Analysis to study riveting operation?

Rivets are used in many ways. For example, in the case of aluminum sheets/structure rivets made up of steel are used. They offer two advantages in this operation first is joining two sheet-metal parts and the second one is the strength at the intersection. Nowadays novel materials are developed and there is extensive research is done in material behavior when used in a certain fashion. It becomes difficult, time-consuming, and costly to perform several tests on actual rivets to understand the physical properties. To perform the actual test making the prototype and then implementing the test as per the verification plan is certainly a complex process. At some point, it can prove to be a mere investment of resources. Using the Finite Element Analysis tool, we can predict these physical properties in less time and cost. We can develop a model to predict several properties in a single simulation and it is convenient to change the design and perform the same simulation. 
As we all know that in 1757 swiss mathematician Leonhard Euler [4] derived the formula for critical load in a column. The Euler's formula [6] has many assumptions such as load is acting through the centroid of the cross-section of a column, Column is made of homogeneous linear elastic material, and the column is perfectly straight.

$$
P_{c r}=\left(\frac{\pi^{2} E I}{(K L)^{2}}\right)
$$

Where, $P_{c r}=$ Critical load

$\mathrm{K}=$ Effective length factor

$\mathrm{E}=$ Modulus of elasticity for the material

$\mathrm{I}=$ Least moment of inertia for the column's cross-sectional area

$\mathrm{L}=$ Length of a column

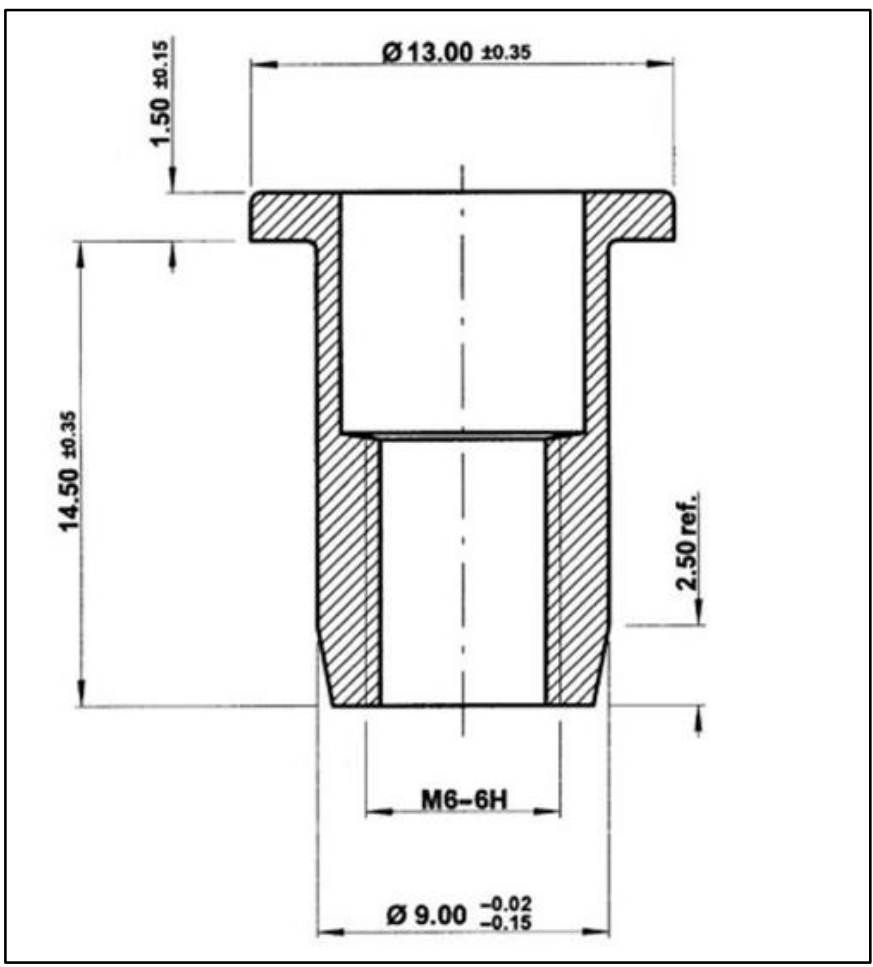

Figure 1-1 POP Nut drawing with dimensions and tolerances provided by Stanley Black \& Decker 


\subsection{Project Scope}

The objective of this study is to understand the material behavior at the neck of the POP Nut (Rivet body) when sufficient load is applied for riveting operation. The inputs required in this study are the true stress-strain curve (plastic properties), Geometry details, and loading criteria.

Many companies are investing resources in developing lightweight mechanisms. To do that they are exploring the materials and channeling the manpower in researching conceptual ideas and probable designs. Previously steel rivets were famous for joining operation but now many industries are moving towards the use of aluminum since it's lightweight and effective in many cases. Research has been done on developing the different aluminum blends with the variable composition of scandium, magnesium to increase mechanical strength and corrosion resistance.

Similar research is going on in Michigan Technological Universities Material Science department. The physical testing of POP Nut made of aluminum and heat-treated at different temperatures was carried out. The buckling load vs displacement curve was derived through this testing.

The axisymmetric model is created in Abaqus to simulate similar test results. The buckling load vs Displacement curve is obtained and compared with physical testing results. We found a good match for the buckling load behavior. For understanding, the friction factor literature study was done and the friction factor of 0.5 was taken in analysis to obtain the results.

Table 1-1. The material composition used in physical testing

\begin{tabular}{|l|l|l|l|l|l|l|}
\hline Alloy 3 & Al & Mg & Mn & Sc & Zr & Zn \\
\hline Target Weight (wt. \%) & Rem. & 5.5 & 0.2 & 0.15 & 0.2 & 0.2 \\
\hline Actual Weight (wt. \%) & Rem. & 5.5 & 0.21 & - & 0.15 & 0.21 \\
\hline
\end{tabular}

Table 1-2. Material composition obtained in the literature study [1,2]

\begin{tabular}{|l|l|l|l|l|}
\hline Alloy 5056 & Al & Mg & Mn & $\boldsymbol{\mu}$ \\
\hline Target Weight (wt. \%) & Rem. & $4.5-5.6$ & 0.2 & 0.5 \\
\hline
\end{tabular}

Based on it can be seen that the Alloy 3 has high magnesium composition, and 5056 aluminum alloy has a chemical composition close to this alloy 3 . 


\section{Model Preparation}

The problem statement defines that the working finite element model needs to provide the buckling load vs displacement result which later can be validated using results obtained from physical testing. The inputs involved in the process are raw material properties, fastener configuration, and fastener application details. The fattener geometry details were obtained from the Stanley Black \& Decker organization.

\subsection{Geometry}

The POP Nut geometry is created using the drawing dimensions provided by Stanley Black \& Decker. The 2D model is created in Abaqus ${ }^{\mathrm{TM}}$. The reason behind developing the $2 \mathrm{D}$ model is to create the axisymmetric model since we were interested in buckling analysis and not in thread breaking. The thread breaking will not occur while performing the riveting operation is assumed in this process.

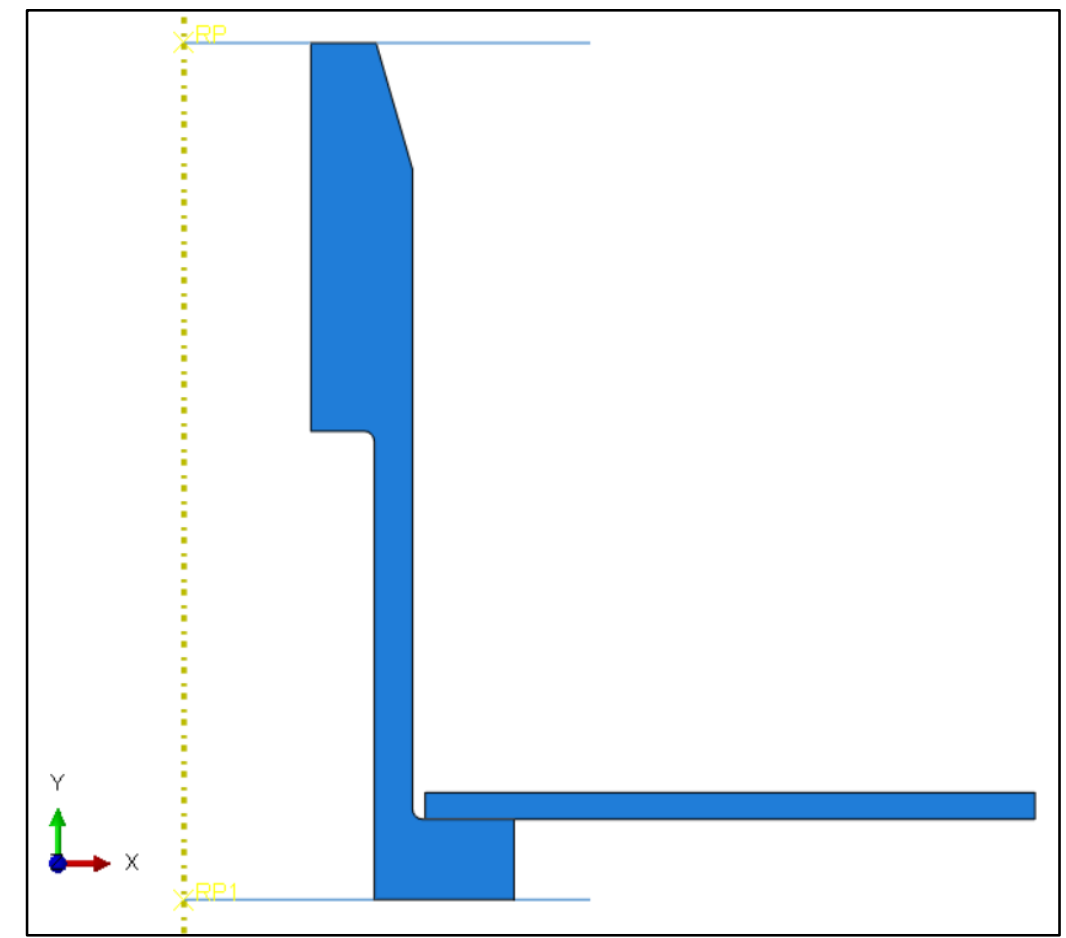

Figure 2-1 POP Nut section with sheet metal.

The dimensions used in the finite element simulation are stated in the following table.

The drawing for the POP Nut is provided with all the geometric tolerances and fits. 
Table 2-1. POP Nut dimensions are taken from drawing provided by Stanley Black \& Decker

\begin{tabular}{|l|l|}
\hline Outer Collar Diameter $(\mathrm{mm})$ & $\mathbf{1 3}^{ \pm \mathbf{0 . 3 5}}$ \\
\hline Collar Thickness $(\mathrm{mm})$ & $1.5^{ \pm 0.15}$ \\
\hline Total Height $(\mathrm{mm})$ & $16^{ \pm 0.50}$ \\
\hline Outer Cylinder Diameter $(\mathrm{mm})$ & $9_{-0.00}^{+0.10}$ \\
\hline Internal Diameter $(\mathrm{mm})$ & 6 \\
\hline
\end{tabular}

The cross-section of the POP Nut is created in Abaqus part modeling with sheet-metal thickness of $0.5 \mathrm{~mm}$ and Two reference points are created to give boundary conditions to the rigid bodies. As the boundary conditions to the rigid bodies cannot be given directly.

The material properties are obtained from the material science department of Michigan technological university. The plastic properties are also used for the POP nut but for the Sheetmetal part, only elastic modulus, poisons ratio, and density are used to define the material.

Table 2-2 Material properties used to define POP nut in analysis

\begin{tabular}{|l|l|}
\hline Material property & Value \\
\hline Elastic modulus $\left(\mathrm{N} / \mathrm{mm}^{2}\right)$ & 66200 \\
\hline Density $\left(\mathrm{Kg} / \mathrm{mm}^{3}\right)$ & 2700 \\
\hline Poisons ratio & 0.33 \\
\hline Yield stress $\left(\mathrm{N} / \mathrm{mm}^{2}\right)$ & 270 \\
\hline
\end{tabular}

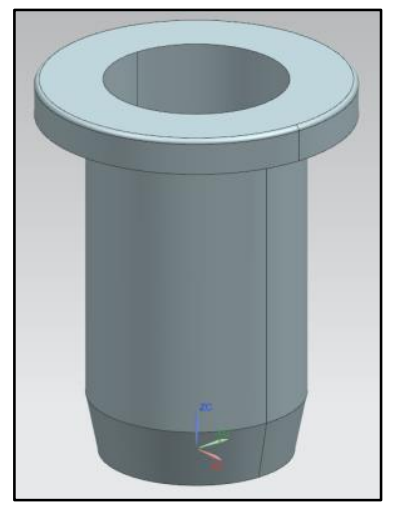

Figure 2-2 CAD model of POP nut modeled in $\mathrm{Nx}$ 


\subsection{Mesh Optimization}

In this model, the mesh sensitivity study is completed. A mesh sensitivity study is used to find out the optimum mesh size for the model. Mesh sensitivity study helps in reducing the simulation time and analysis cost. In this case, the initial mesh size was taken 0.25 $\mathrm{mm}$. and subsequently, mesh size is reduced, and the model is simulated to obtain stress values in the bulge formed region. This H-refinement can be seen on the graph it shows that the stress variation between $0.0625 \mathrm{~mm}$ and $0.025 \mathrm{~mm}$ is very less. This means reducing the mesh below 0.025 will not have a great impact on the results.

Table 2-3 Mesh size with stress values from the mesh sensitivity study

\begin{tabular}{|l|l|}
\hline Mesh Size & Stress $\left(\mathbf{N} / \mathbf{m m}^{2}\right)$ \\
\hline 0.250 & 489.8 \\
\hline 0.125 & 498.6 \\
\hline 0.100 & 513.5 \\
\hline 0.062 & 562.4 \\
\hline 0.050 & 563.5 \\
\hline 0.035 & 570.5 \\
\hline 0.025 & 578.7 \\
\hline
\end{tabular}

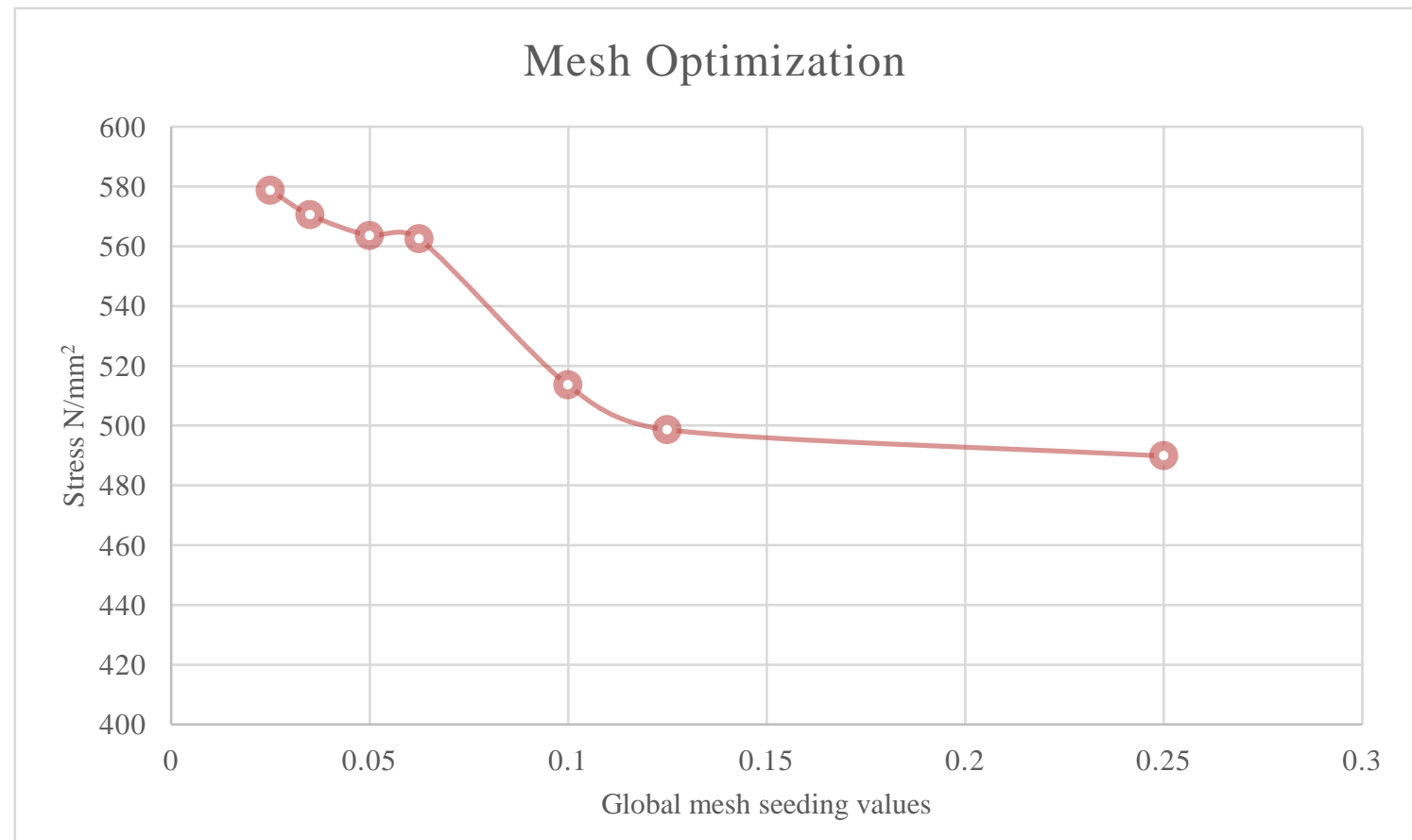

Figure 2-3 POP Nut mesh optimization study with global mesh seeding. 
Based on the mesh sensitivity study the global mesh size of $0.05 \mathrm{~mm}$ is taken into consideration for the model. The axisymmetric CAX4R elements were selected. CAX4R [5] are regular axisymmetric elements that belong to the continuum family of elements. When applied, they offer reduced integration and hourglass control. Globally seeded mesh with these elements was checked for rotational elements.

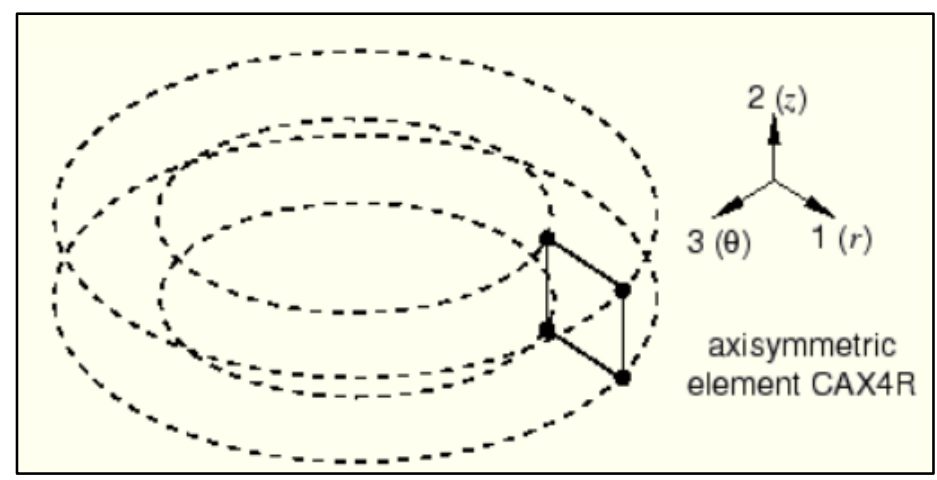

Figure 2-4 CAX4R axisymmetric element suitable to analyze structure with axisymmetric geometry [5]

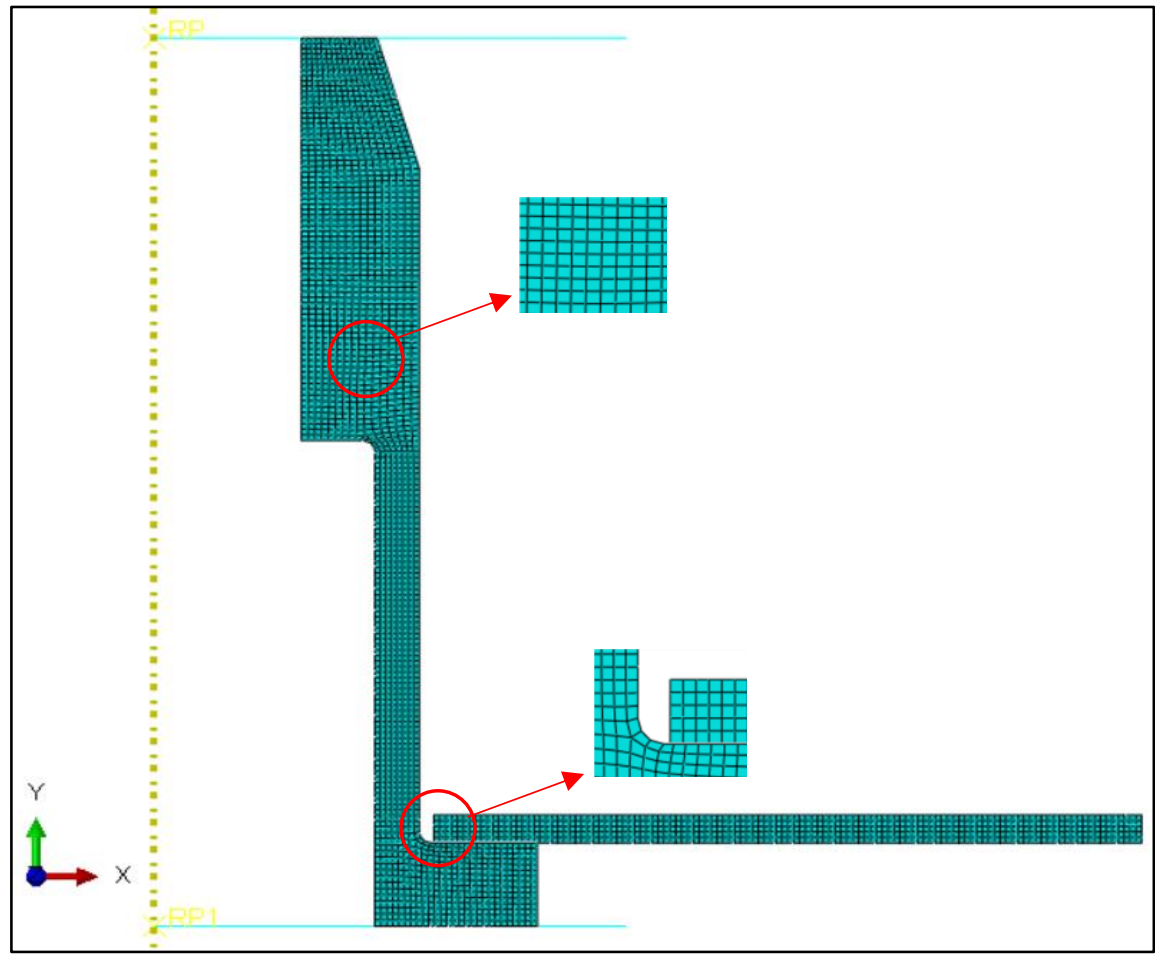

Figure 2-5 Meshed POP Nut section assembly with global mesh seeding of $0.05 \mathrm{~mm}$ 
In the element quality check, the mesh verification tool from Abaqus is used. In mesh verification, there are two quality matrices. These are shape matrices and size matrices. In shape matrices, the aspect ratio is checked. For this analysis, the average aspect ratio was found out to be 1.15 and the max aspect ratio was observed to be 2.66 . In size matrices, the geometric deviation factor was checked. The geometric deviation factor gives us the edge deviation of the element from the original geometry. The max geometric deviation was found out to be 0.0853 and the average value was detected to be $1.84 \times 10^{-4}$.

After quality checks, the mesh is checked for rotational elements. Few rotational elements were found in the model. To remove the rotational elements the global seeding was adjusted using edge seeding. 


\subsection{Boundary condition and setup}

As states previously, the axisymmetric model is created in Abaqus. In the actual application of POP Nut, the mandrel is used to pull the nut against sheet-metal parts. In this simulation, the displacement is applied to the back of the POP nut. The displacement of $6 \mathrm{~mm}$ is applied in the negative Y-direction to the reference point created for top rigid elements. The Sheetmetal part and the rigid elements created at the base are constrained in $\mathrm{x}, \mathrm{y}, \mathrm{z}$ directions.

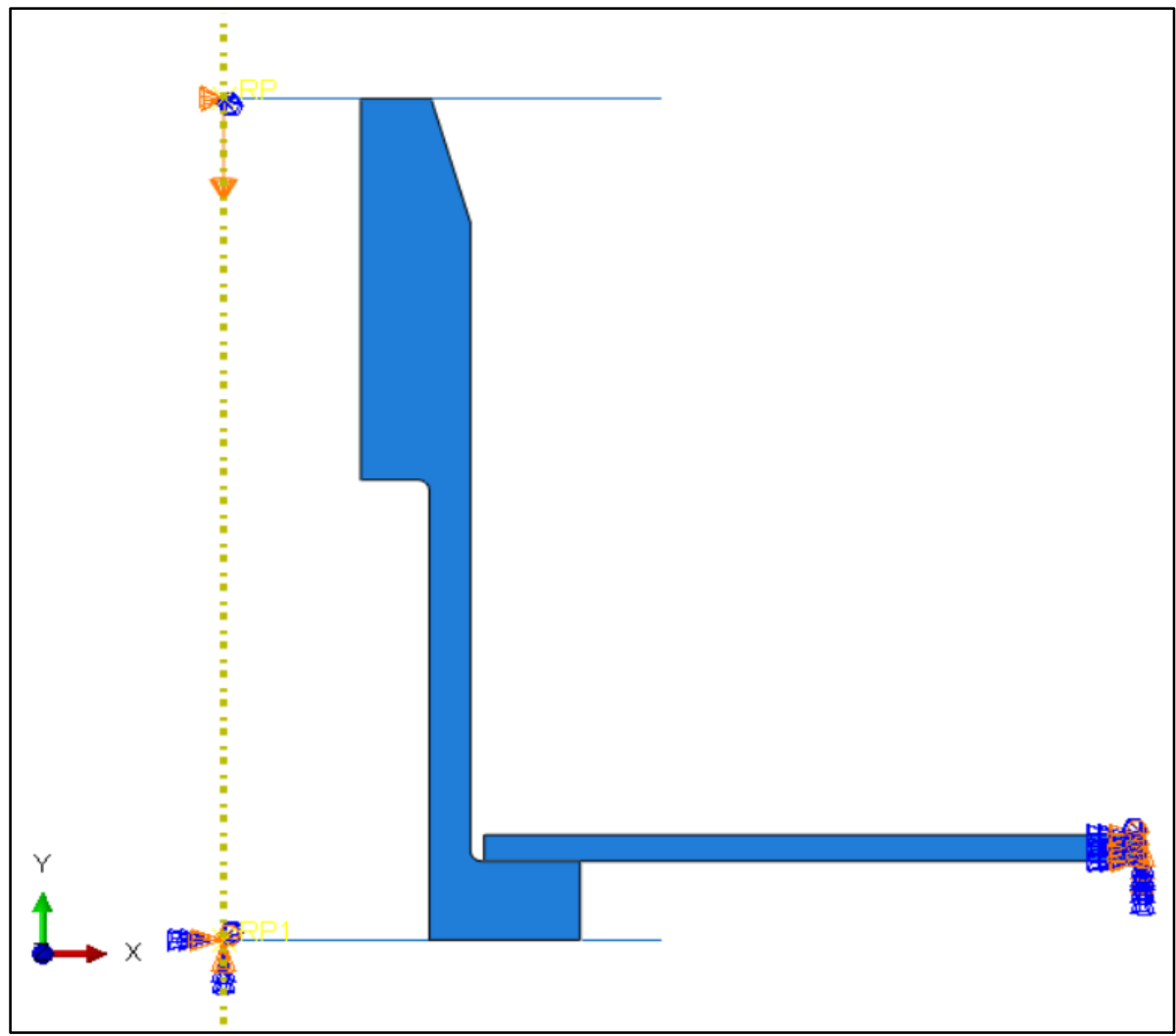

Figure 2-6 Boundary conditions and reference points in model setup

The material properties are given to the POP Nut section and Sheetmetal part. The analysis involves the contact properties. There are surface-to-surface contact and selfcontact. Penalty-based interaction properties are used to implement these contracts. Based on the literature study the friction factor used in the analysis is 0.5. In surface-to-surface contact, the Sheetmetal part is made master surface and the POP Nut outer region is considered as the slave surface. Self-contact is defined on the inner surface of the POP Nut. Along with this, the tie constraints are created between the reference point assigned to top rigid elements and POP Nut, reference point assigned to bottom rigid elements, and POP Nut, between Sheetmetal surface and POP Nut collar. 


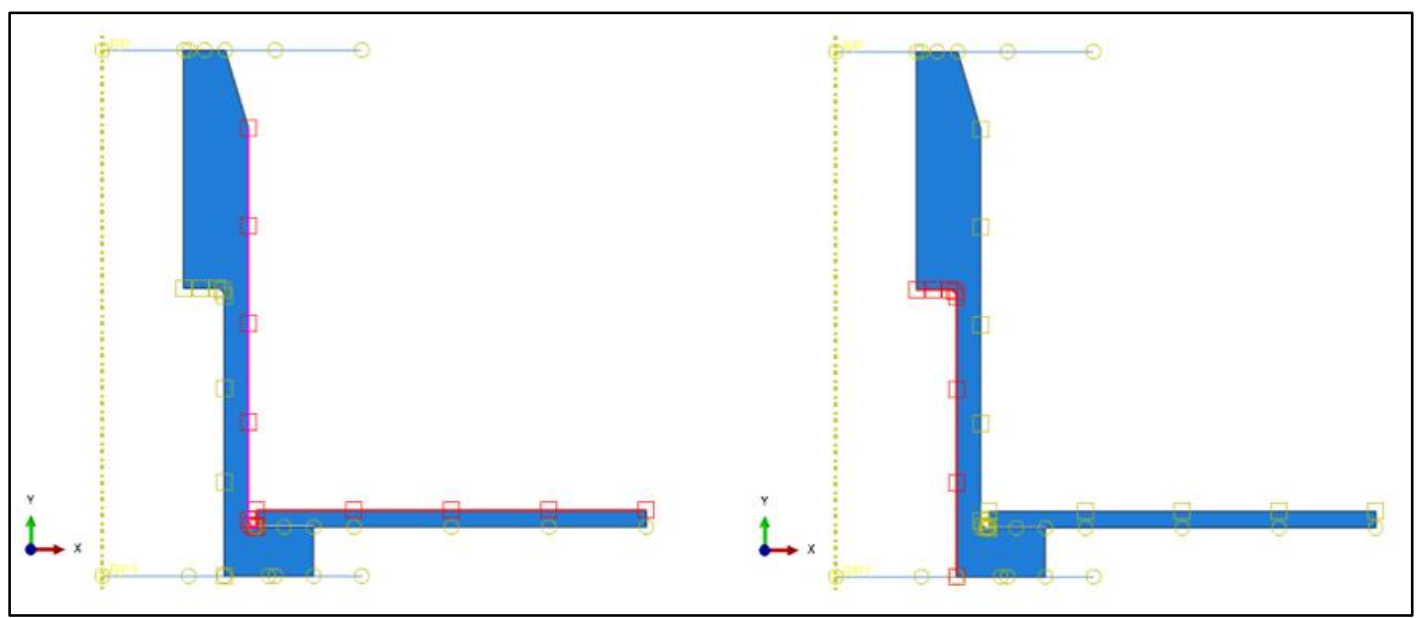

Figure 2-7 Contact surfaces in POP nut assembly. On left surface-to-surface contact and on right self-contact

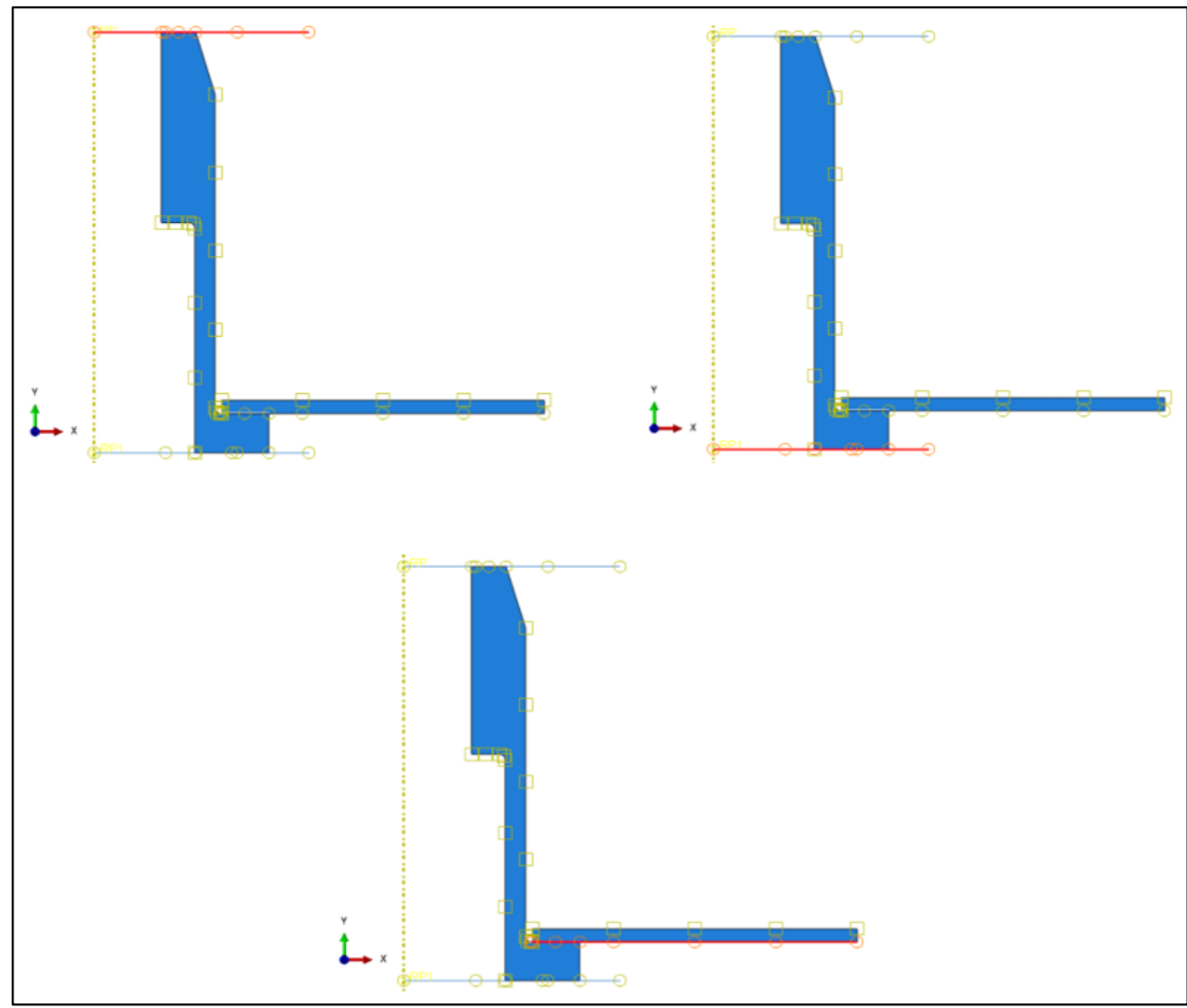

Figure 2-8 Tie constraints in POP nut assembly. From left between the top surface of rivet and reference point on upper rigid elements, between reference point on lower rigid elements and POP nut collar, and between Sheetmetal and POP nut collar, and between the collar of a rivet 


\section{Results}

The stress distribution over the POP nut was observed and It can be seen stress distribution in the bulge formation region is uniform.

\subsection{Stress contour in POP nut assembly}

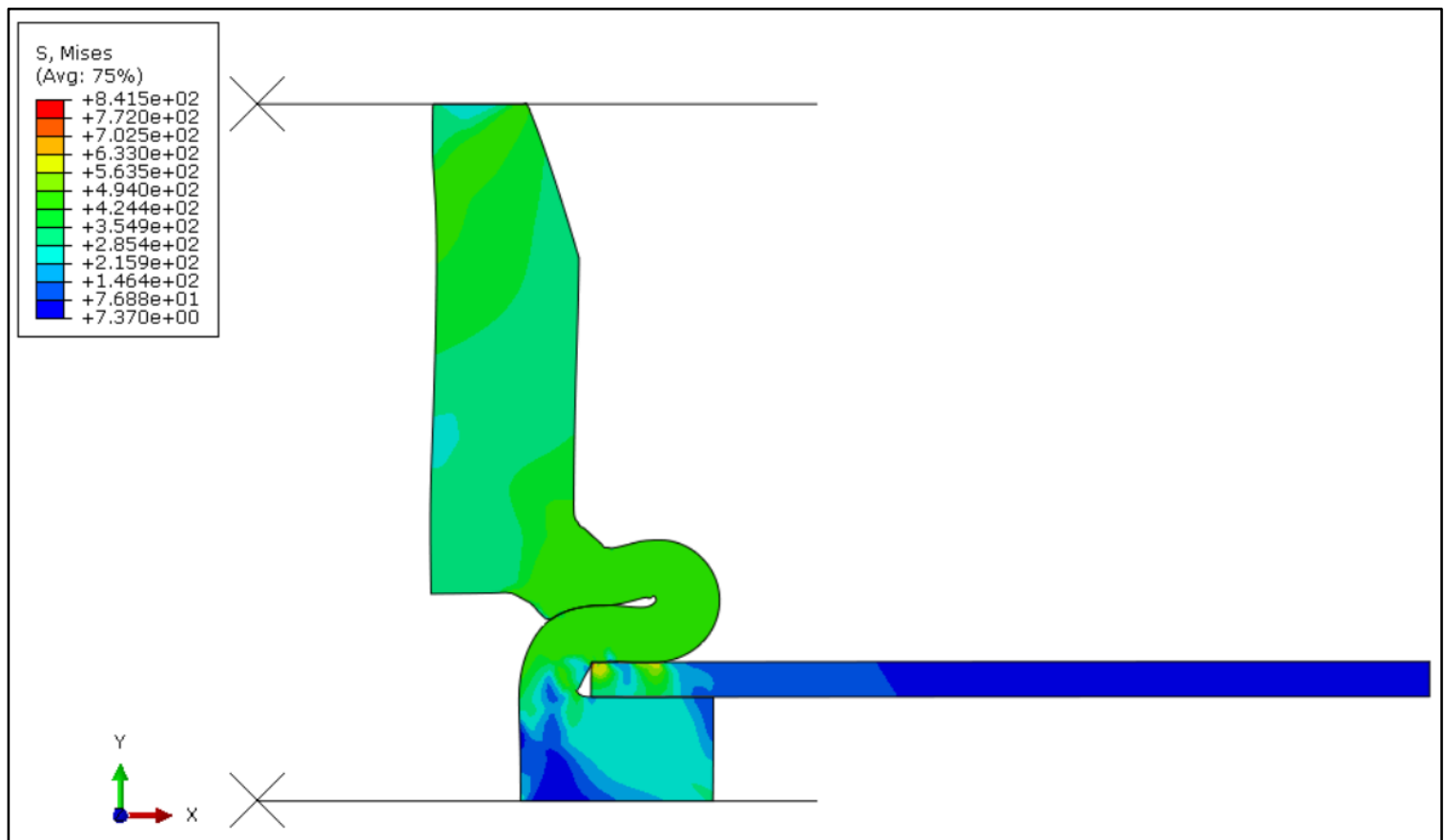

Figure 3-1 Stress distribution in POP nut assembly after $6 \mathrm{~mm}$ displacement.

Stress singularity is observed in the Sheetmetal part. The buckling load vs displacement curve is plotted for the given finite element analysis. It is found that during the physical testing aluminum alloy with heat treatment at $600^{\circ} \mathrm{C}$ shows no crack. The analysis performed in Abaqus does not consider heat treatment. 


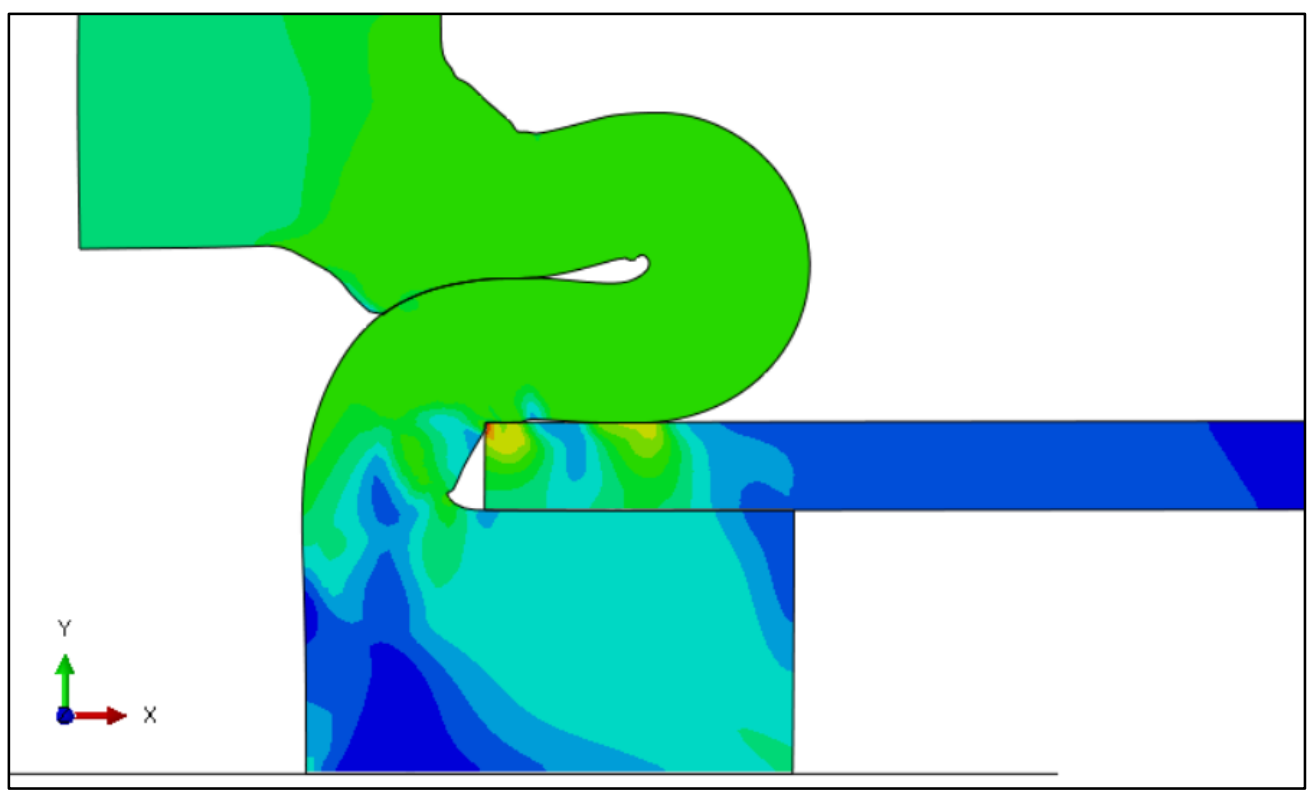

Figure 3-2 Stress singularity observed in the Sheetmetal part.

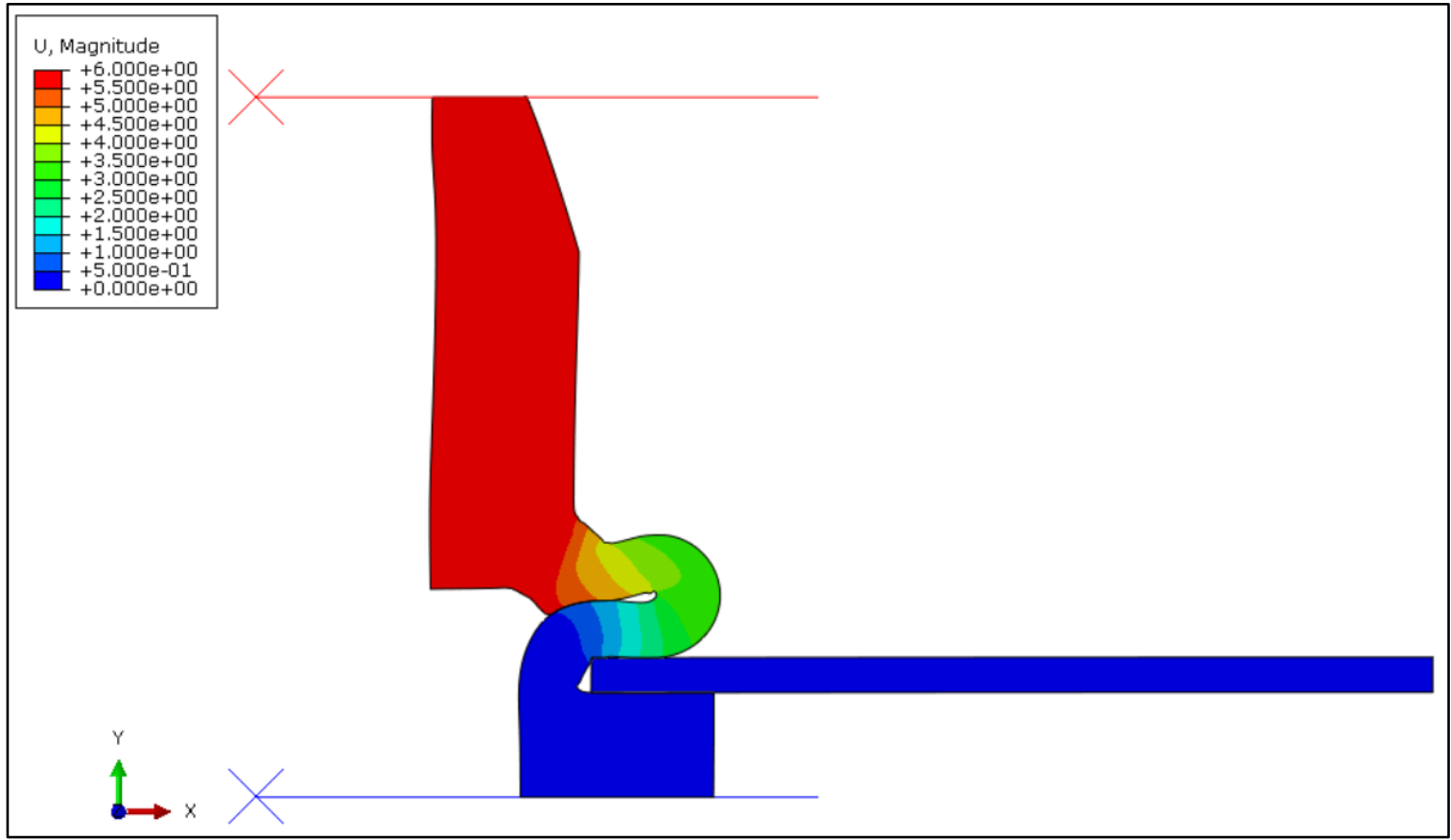

Figure 3-3 Displacement contour for POP nut assembly. 


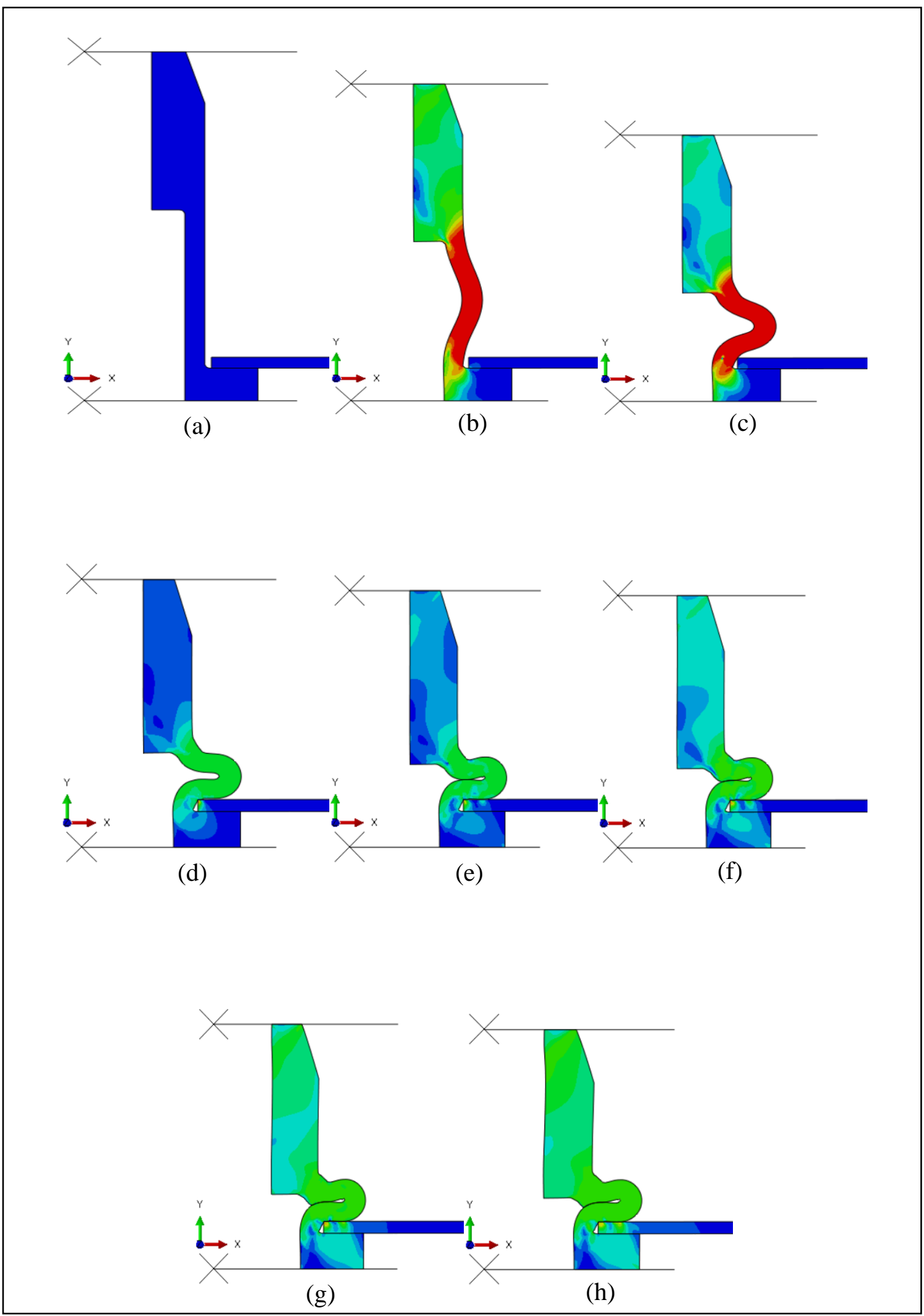

Figure 3-4 POP nut assembly stress contour at every 25 timesteps. 


\subsection{Testing results and Finite Element Analysis results}

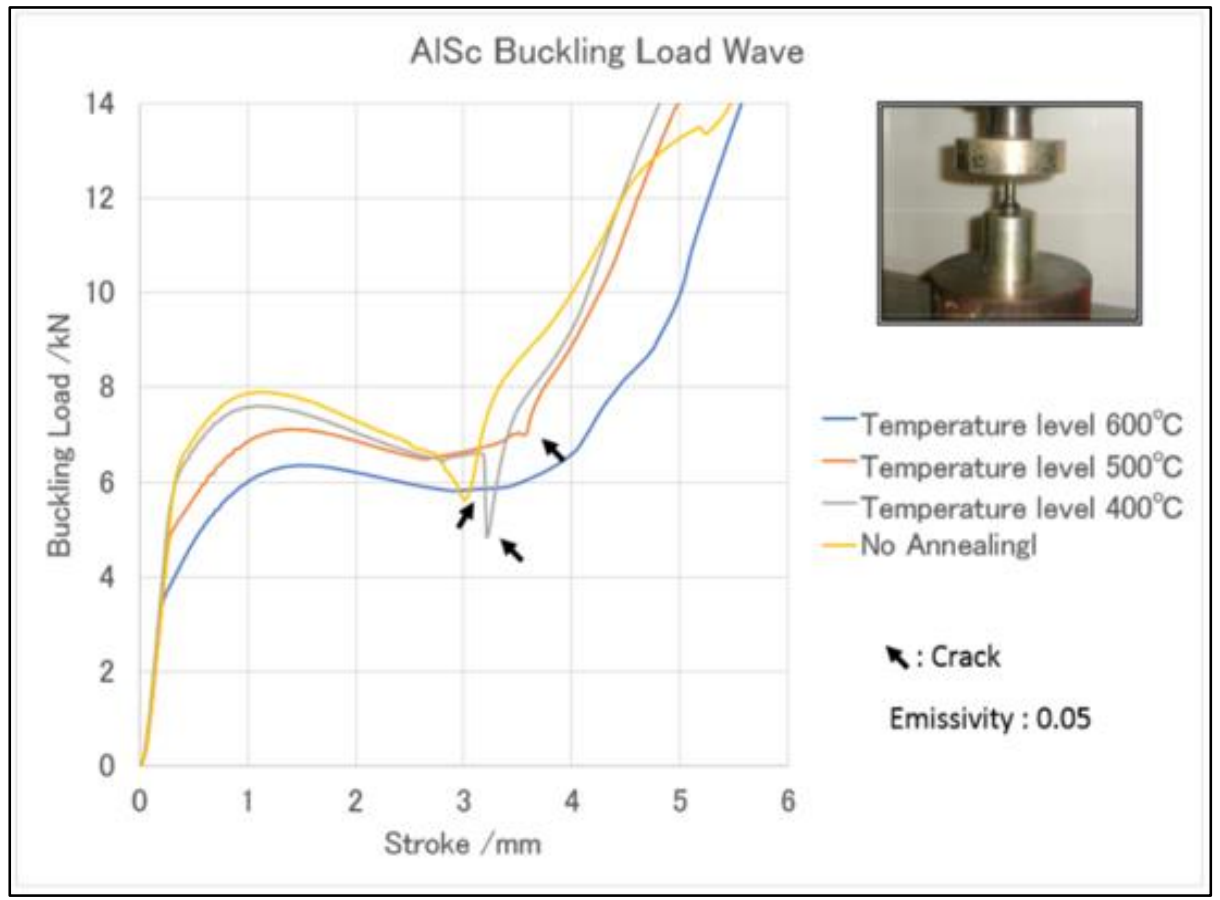

Figure 3-5 Buckling load vs displacement curve from physical testing

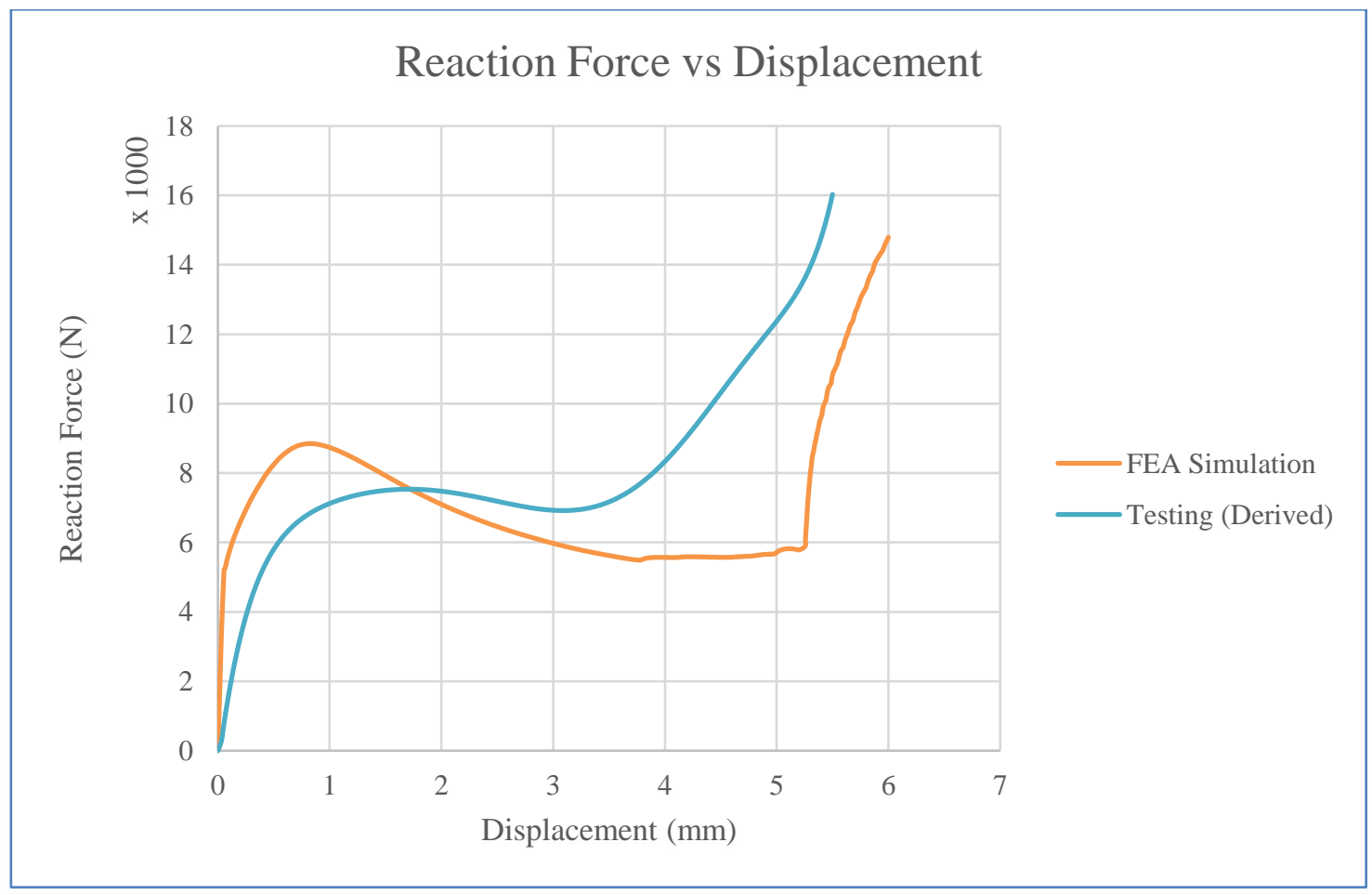

Figure 3-6 Buckling load vs Displacement curve comparison 
After completing the analysis, from history output request reaction force vs displacement at the reference point is selected. From simulated results, the buckling load vs displacement curve is plotted and compared with physical testing results. The finite element analysis results are in good agreement with the actual data.
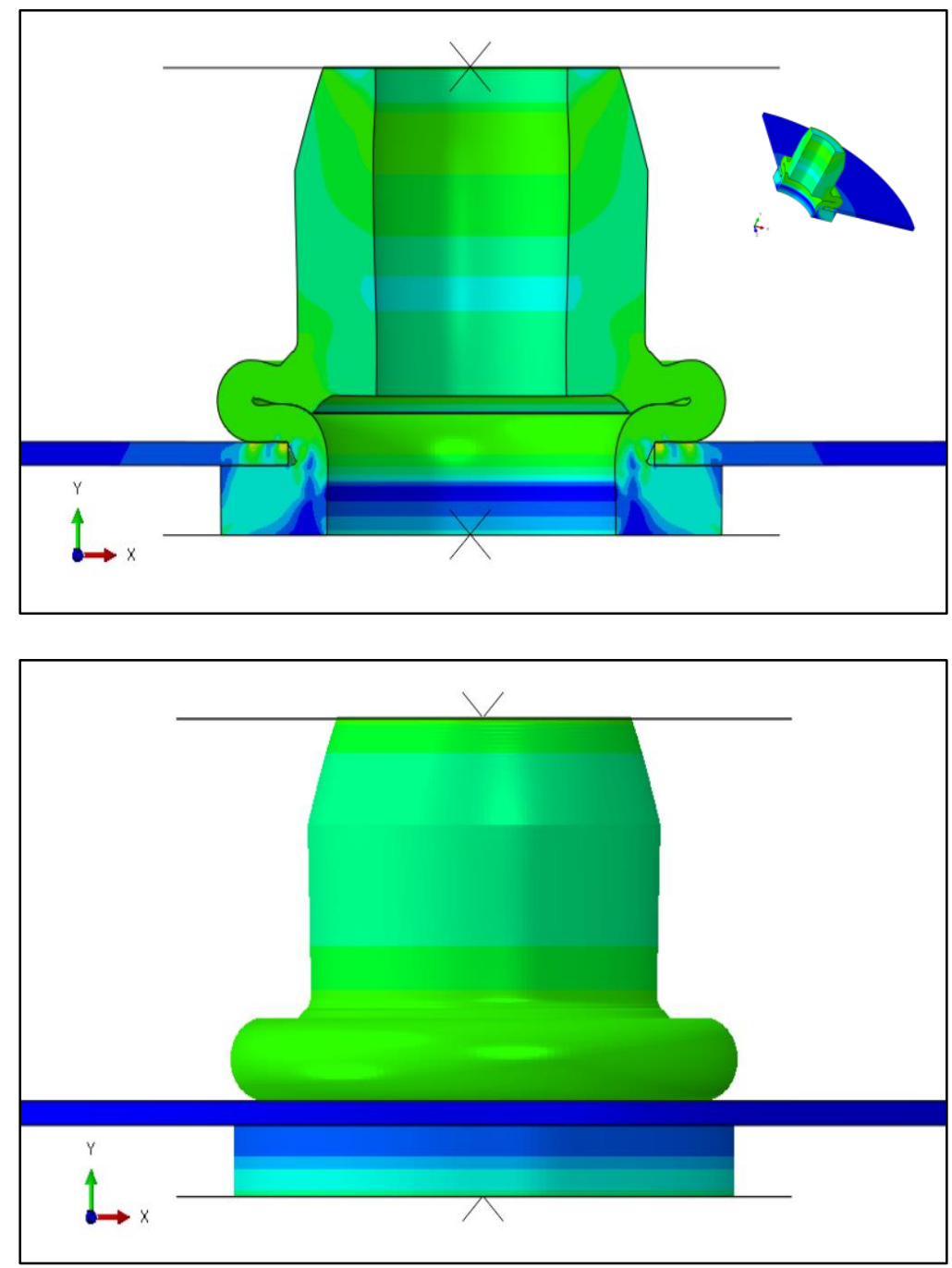

Figure 3-7 $180^{\circ}$ and $360^{\circ}$ sweep of POP nut assembly at the final timestep.

There is a slight deviation between 5 to $6 \mathrm{~mm}$ displacement this could be because of stress singularity. Also, in the blanking process, the edge of the blanked part will not be absolutely in the right angle. In every case, there is a slight curvature and it is because no process is $100 \%$ perfect. To make that edge close to right angle high precision and GD\&T are required which is again costly and does not add value to the process. 


\section{Conclusion}

Contact properties and constraints are the key parameters in successfully running the finite element analysis of this project. The analysis results are in good agreement with physical testing results. Understanding the riveting process and material properties are essential in building the FEA model. Simulating with the axisymmetric model proved to be less time consuming and simpler than the actual 3D model. The FEA simulation time drastically reduced when the axisymmetric model is built for the analysis. It simplified the mesh, boundary conditions, and complex CAD geometry.

After performing the simulation on given alloy, it followed the same trend as seen from physical testing. This FEA model can be used to obtain the buckling load trend in different materials. It will eliminate the destructive testing and cost associated with it. The cross-validation of the FEA analysis and physical testing can be helpful to develop the complex scenarios in these kinds of operations. 


\section{Future work recommendations}

Based on the results it can be seen that there is a slight deviation between the physical test and FEA results. The possible reasons could be stress singularity, Sheetmetal material properties, Heat treatment. Carefully understanding the process and building the FEA model by incorporating heat treatment and Sheetmetal material properties will give a better correlation.

The four key points that can be considered to improve the existing FEA model:

1. Perform FEA analysis taking into consideration the blanking process and stress singularities

2. Perform full model analysis instead of the axisymmetric model

3. Incorporate the mandrel and threads in the model and perform the analysis by proving the loading condition on the mandrel.

4. Cross validate the results from FEA analysis with different materials to the physical testing results. 


\section{Reference List}

1. Free J.C., Summers P.T., Lattimer B.Y., Case S.W. (2016) Mechanical Properties of 5000 Series Aluminum Alloys Following Fire Exposure. In: The Minerals, Metals \& Materials Society (eds) TMS 2016 145th Annual Meeting \& Exhibition. Springer, Cham

2. Sujatanond, Supamard, Yukio Miyashita, Shinji Hashimura, Yoshiharu Mutoh, and Yuichi Otsuka. "Bolt Load Loss Behavior of Magnesium Alloy AZ91D Bolted Joints Clamped with Aluminum Alloy A5056 Bolt." Applied Mechanics and Materials 313314 (March 2013): 135-39.

3. Abaqus/CAE 2018

4. Hibbeler, R. C. 2003. Mechanics of materials. Upper Saddle River, N.J.: Pearson Education

5. Abaqus (2018), Abaqus Documentation, Dassault Systems, Providence, RI, USA.

6. “Column Buckling.” MechaniCalc. Accessed April 24, 2020. https://mechanicalc.com/reference/column-buckling. 